Гулькова Елена Леонидовна

канд. экон. наук, ФГБОУ ВО

«Государственный университет

управления», г. Москва

e-mail:Lega05@mail.ru

Карп Марина Викторовна д-р экон. наук, ФГБОУ ВО «Государственный университет управления», г. Москва

e-mail: Marvik-09@mail.ru

Типалина Мария Валерьевна канд. экон. наук, ФГБОУ ВО «Государственный университет управления»,

г. Москва

e-mail: mariatipalina@yandex.ru

\section{Gulkova Elena}

Candidate of Economic Sciences, State University of Management, Moscow e-mail:Lega05@mail.ru

\section{Karp Marina}

Doctor of Economic Sciences, State University of Management, Moscow e-mail: Marvik-09@mail.ru

\section{Tipalina Mariya}

Candidate of Economic Sciences, State University of Management, Moscow e-mail: mariatipalina@yandex.ru

\section{НАЛОГОВЫЕ ВЫЗОВЫ ЦИФРОВОЙ ЭКОНОМИКИ}

\begin{abstract}
Аннотация. Исследованы вопросы изменения налоговой системы Российской Федераичи, системы налогового контроля под влиянием ијифровых технологий. Рассмотрены электронные государственные услуги в сфере налогообложения, а также определень перспективы и направления дальнейшего развития и расширения применяемых электронных сервисов для налогоплательщиков и налоговых органов. Затронуты проблемы налогообложения операций с криптовалютами и их налогового регулирования. Сформулированы выводы по повышению эффективности налогообложения и налогового контроля в условиях перехода к ичировой экономике.
\end{abstract}

Ключевые слова: налоговая система, иифровые технологии в налогообложении, налоговое регулирование, иифровые финансовые активы, цифровая экономика.

\section{TAX CHALLENGES OF THE DIGITAL ECONOMY}

\begin{abstract}
The issues of changing the tax system of the Russian Federation, the system of tax control under the influence of digital technologies have been examined. Electronic government services in the field of taxation, as well as the prospects and directions for the further development and expansion of electronic services used for taxpayers and tax authorities have been considered. The problems of taxation of operations with cryptocurrencies and their tax regulation have been touched upon. Conclusions have been formulated to improve the efficiency of taxation and tax control in the transition to a digital economy.
\end{abstract}

Keywords: tax system, digital technologies in taxation, tax regulation, digital financial assets, digital economy.

В последние годы цифровая трансформация экономики является в Российской Федерации (далее - РФ) одним из главных приоритетов. В целях реализации концепции развития информационного общества была утверждена программа «Цифровая экономика Российской Федерации». Можно выделить два основных подхода к трактовке понятия «цифровая экономика», которые опираются на исследования российских и зарубежных ученых в данной области. В это определение включают все направления экономических отношений, в основе которых лежат информационные технологии и телекоммуникации $[5 ; 6 ; 10]$.

Влияние цифровой экономики на налоговую систему РФ можно обозначить в четырех аспектах:

- внедрение и оказание цифровых государственных услуг Федеральной налоговой службой (далее ФНС) России;

- автоматизированная система налогового контроля;

- создание благоприятных налоговых условий для стимулирования инвестиций в цифровые технологии;

- определение и разработка механизма налогообложения новых продуктов, операций, возникших в связи с применением цифровых технологий.

На сегодняшний день растет количество и качество электронных государственных услуг [7]. Существует единый портал бюджетной системы РФ, предоставляющий в режиме реального времени необходимую информацию о бюджете и бюджетном процессе в РФ. Для главных распорядителей средств электронный бюджет дает возможность проектировать, контролировать, исполнять бюджет совместно со своими подведомственными

(С Гулькова Е.Л., Карп М.В., Типалина М.В., 2019. Статья доступна по лицензии Creative Commons «Attribution» («Атрибуция»)

4.0. всемирная (http://creativecommons.org/licenses/by/4.0/).

The Author(s), 2019. This is an open access article under the CC BY 4.0 license (http://creativecommons.org/licenses/by/4.0/).

(c) (i) 
учреждениями в единой базе данных в онлайн-режиме. Реализация данных функций осуществляется посредством «личных кабинетов» с защищенным доступом. В открытом доступе находится нормативная, статистическая и аналитическая информация в области общественных финансов, например, в доступной форме информация о бюджетной политике, показателях различных уровней содержится в документе «Бюджет для граждан» [11].

В сфере налогообложения государственные услуги оказывает ФНС России. Каждому налогоплательщику предоставляется доступ к личной налоговой информации. Например, электронный сервис «Личный кабинет юридического лица» позволяет направлять запросы и заявления в налоговую инспекцию, получать выписки, информацию о начисленных и уплаченных суммах налогов, задолженности и т. д. Электронный сервис «Личный кабинет физического лица» предоставляет возможность обмениваться информацией с налоговой инспекцией, заполнять декларации 3-НДФЛ онлайн, отслеживать статус их камеральной проверки, контролировать состояние расчетов с бюджетом. Для физических лиц, которые являются индивидуальными предпринимателями или плательщиками налога на профессиональный доход, представлены отдельные сервисы, позволяющие им выполнять необходимые для их деятельности функции. Помимо вышеуказанного, существует электронный сервис «Государственная регистрация юридических лиц, индивидуальных предпринимателей», который обеспечивает подготовку полного комплекта необходимых документов для создания компании или ИП, заполнение заявления и его отправки в налоговый орган, на который возложены функции регистрации. Кроме того, обеспечена возможность в электронном виде получить информацию из различных реестров. Например, из Единого государственного реестра юридических лиц и Единого государственного реестра индивидуальных предпринимателей, федеральной информационной адресной системы, из реестра арбитражных управляющих и т. д. Предлагаются сервисы, позволяющие в электронном виде сформировать платежные документы на уплату налогов, проверить корректность заполнения счетов-фактур, провести расчеты стоимости патента, имущественных налогов физических лиц, выбрать режим налогообложения с помощью представленных налоговых калькуляторов. В сфере регулирования налогообложения иностранных компаний необходимо отметить «НДС-офис интернет-компании», который позволяет проверить, нужно ли иностранной компании, ведущей деятельность в сфере электронных услуг в РФ, встать на учет в налоговых органах. При необходимости, сервис предоставляет возможность заполнить и подать заявление о постановке на учет, после которой интернет-компании будет доступен личный кабинет с функциями представления декларации по налогу на добавленную стоимость, осуществления обмена документами, письмами с налоговым органом и т. д.

Кроме того, разработаны и функционируют электронные сервисы ФНС России, позволяющие в электронном виде, без личного посещения налоговых органов, получить или передать необходимую информацию, заполнить документацию. К таким, например, относятся: «риски бизнеса», «обратиться в ФНС России», «узнать о жалобе», «представление отчетности в электронном виде», «проверить статус налогового резидента Российской Федерации» и иная справочная информация [13].

Совершенствуется не только оказание государственных услуг организациям и гражданам, но методика и инструменты налогового контроля. Кроме автоматизированной информационной системы ФНС России «Налог», которая модернизируется, обновляется и используется при осуществлении налоговых проверок и иных мероприятий налогового контроля, запущена автоматизированная система контроля за возмещением налога на добавочную стоимость (далее - НДС). Данная система позволяет в автоматическом режиме контролировать цепочки создания добавленной стоимости. Основная ее функция - посредством анализа электронных деклараций НДС определить налоговые риски налогоплательщиков и предотвратить незаконные вычеты и возмещения данного налога. На современном этапе можно констатировать повышение качества администрирования в связи с внедрением инструментов дистанционного цифрового контроля. Активную роль также играет использование контрольно-кассовой техники с онлайн-передачей информации. На сегодняшний день уже более 821 тыс. налогоплательщиков применяют 2,3 млн касс. В сутки пробивается 120 млн чеков на 70 млрд рублей. При этом средняя выручка на одну кассу увеличилась в два раза. Все это способствует тому, что налоговые поступления в бюджет продолжают расти.

В ближайшие три года планируется продолжение работы по созданию единого механизма сквозного контроля на всех этапах оборота импортных товаров, подлежащих прослеживаемости. Особенностью системы прослеживаемости (далее - НСП) будет являться полностью электронный документооборот счетов-фактур и универсальных передаточных документов между уполномоченным федеральным органом исполнительной 
власти по созданию, внедрению и сопровождению НСП и налогоплательщиками, в том числе применяющими специальные режимы налогообложения, при продаже импортных товаров. В ближайшие годы запланировано дополнение в структуре контроля за физическим движением товаров с помощью маркировки (физические потоки будут сопоставляться с финансовыми). Наблюдение за финансовыми взаимоотношениями физических лиц меду собой планируется с помощью реализации права запрашивать у банков информацию о счетах физических лиц вне осуществления налоговых проверок (благодаря встроенному в информационную систему службы реестру записей актов гражданского состояния ФНС имеет информацию о родственных связях российских граждан), что даст возможность налоговым органам контролировать денежные взаимоотношения между физическими лицами и выявлять незаконное предпринимательство. Результатами проводимой работы должно стать дальнейшее увеличение платежей в бюджеты всех уровней, обеление соответствующих секторов экономики, повышение конкурентоспособности отечественного производства. К 2035 г. ФНС обещает настолько тесно внедриться в жизнь компаний и людей, что обеспечит практически «автоматическое» выполнение налоговых обязательств. Сама ФНС превратится в «адаптивную платформу», работающую в режиме реального времени с цифровыми источниками данных и с цифровыми идентичностями налогоплательщиков. Таким образом, к 2035 г. российская экономика может стать полностью прозрачной.

Несмотря на существующие механизмы развития налогового регулирования и администрирования, в условиях цифровизации российской экономики все еще остается ряд нерешенных проблем. В последнее время идет активное обсуждение трудностей определения правового поля вокруг отношений, возникающих при генерировании, хранении и обращении цифровых финансовых активов, к которым отнесены криптовалюта и токен. Поэтому задачами, требующими решения, являются разработка и конкретизация механизма налогообложения новых продуктов и операций в цифровой экономике, а именно: функционирование таких инструментов общественных финансов как цифровые деньги [9]. На первый план выходят: установление с позиции права интерпретации в законодательных актах РФ определения данных финансовых инструментов; разработка целей и принципов правового регулирования цифровых денежных отношений; определение оптимального соотношения национальных и международных стандартов при регулировании данного вида финансовых инструментов и другие, не менее важные вопросы. Во взаимосвязи современных экономических отношений и цифровизации экономики, необходимо выявить, к каким инструментам финансовых отношений будут относиться цифровые деньги с позиции юридически значимых правомерных действий субъектов права.

Вопросы о выделении электронных денег как самостоятельной категории денежных средств, в частности криптовалют, функционирующих на основе технологии блокчейн, либо отнесение данных видов отношений к другой категории финансовых взаимоотношений порождают множество разногласий в самой трактовке данных цифровых инструментов с позиции правовой теории и практики [8]. Недостаточное понимание аспектов их регулирования (например, какими отношениями являются финансовые операции с криптовалютами с позиции права), не дает сложившегося конкретного представления о концепции, становлении, а также продвижении в области научных и практических подходов к фискальным налоговым отношениям.

Если рассматривать цифровые деньги в экономическом и правовом поле России, то одним из вариантов конкретизации правового статуса можно выделить их отнесение к валюте. В данном случае, регулирование будет осуществляться с помощью Федерального закона «О валютном регулировании и валютном контроле», который создает основу валютного законодательства и утверждает полномочия и обязательства физических и юридических лиц в области взаимодействий, связанных с валютой [2]. Кроме этого, регламентирует правовые принципы валютного контроля и регулирования, определяет полномочия и обязательства участников отношений, связанных с валютными ценностями и их использованием, устанавливает полномочия органов валютного регулирования, правила и порядок проведения регулирования и контроля относительно валютных операций. Однако нельзя забывать о том, что основной принцип использования валюты определен ст. 140 и ст. 317 Гражданского Кодекса РФ, которые утверждают рубль в качестве законного платежного документа в РФ [1]. Валютные операции между резидентами запрещены по общему правилу, но разрешены для сделок между уполномоченными банками, совершаемым ими от своего имени и за свой счет и некоторые валютные операции между резидентами и уполномоченными банками (ч. 1, 2, 3 ст. 9 Закона 173-ФЗ). Тем не менее, юридические лица-резиденты вправе без ограничений осуществлять валютные операции со средствами, зачисленными на счета (во вклады), открытые в банках за пределами территории РФ, за исключением валютных операций между 
резидентами. Для отражения в учете и отчетности стоимостные значения обязательств и активов юридических лиц, а также величина запасов, выраженные в иностранной валюте, должны быть пересчитаны в рубли. Разница в рублях, возникающая при пересчете валютной стоимости активов и обязательств на разные даты по итогам отчетного периода относится к финансовому результату компании и, соответственно, уплачивается налог на прибыль. Физические лица-резиденты вправе без ограничений осуществлять валютные операции, не связанные с передачей имущества и оказанием услуг на территории РФ, с использованием средств, зачисленных на счета (во вклады), открытые в банках за пределами территории РФ. Непосредственно проведение операций для физических лиц с валютой, наличной или безналичной, никаким специальным налогом не облагается. Таким образом, законным средством платежа на территории России является национальная валюта. Что же касается иностранных валют, то в отношении них действует особый режим, установленный валютным законодательством.

Имущественные отношения складываются по поводу конкретного имущества - материальных, нематериальных благ и имущественных прав, которые возникают по результатам работ, оказания услуг и могут выражаться не только в вещественном результате, однако должны быть связаны с экономикой, иметь стоимостной характер, т. е. являться имущественно-стоимостными. Гражданский кодекс РФ, перечисляя в ст. 128 объекты гражданских прав, относит безналичные средства к иному имуществу (безналичные деньги, бездокументарные ценные бумаги, имущественные права). В зависимости от формы денежных средств есть соответствующие особенности в их правовом режиме. В частности, электронные деньги согласно закону «О национальной платежной системе», являются имуществом (разновидностью безналичных денежных средств) [3]. Иностранные денежные средства также являются имуществом, но, как было указано выше, их использование в гражданском обороте ограничено.

Криптовалюта представляет собой новую технологию, выпуск, обмен и учет которой основываются на криптографическом принципе (шифровании). Единицей измерения цифровых денег являются коины. Все криптовалюты основаны на технологии блокчейн - цепочке из информационных блоков, выстроенных в строгой последовательности и по определенным правилам. В данном случае вести учет, хранить данные, совершать транзакции можно в любой сфере [9]. Платформа блокчейн выступает как база данных для общего пользования, где преимущественно отсутствует централизованный надзор над процессом. Номинальная стоимость криптовалюты не гарантирована, курс зависит исключительно от востребованности пользователями. На сегодняшний день насчитывается более семисот видов криптовалют. Самой востребованной из них является биткоин, который признан на государственном уровне в большинстве стран и используется как инструмент инвестиций, не имеет реального выражения, но может принимать участие в рыночных операциях наравне с обычными деньгами (табл. 1). Например, в Германии разрешены операции с биткоинами, как вариант расчетов; в Японии биткоин является платежным средством с налогом на покупку; в Китае операции с биткоинами запрещены для банков, но разрешены для физических лиц.

Таблиия 1

Правовой статус и налогообложение криптовалют в различных странах

\begin{tabular}{|c|c|c|}
\hline Государство & Правовой статус криптовалюты & $\begin{array}{c}\text { Налогообложение операций } \\
\text { с криптовалютами }\end{array}$ \\
\hline Австралия & имущество & $\begin{array}{l}\text { налог на прибыль; } \\
\text { подоходный налог }\end{array}$ \\
\hline Австрия & нематериальный актив & подоходный налог; \\
\hline Великобритания & платежное средство & $\begin{array}{l}\text { корпоративный налог; } \\
\text { подоходный налог }\end{array}$ \\
\hline Германия & валюта & $\begin{array}{l}\text { налог на прирост капитала; } \\
\text { налог на богатство; } \\
\text { НДС }\end{array}$ \\
\hline Израиль & товар & $\begin{array}{l}\text { налог на прибыль; } \\
\text { налог на прирост капитала }\end{array}$ \\
\hline
\end{tabular}


Окончание табл. 1

\begin{tabular}{|c|c|c|}
\hline Государство & Правовой статус криптовалюты & $\begin{array}{c}\text { Налогообложение операций } \\
\text { с криптовалютами }\end{array}$ \\
\hline Испания & валюта & налог на прибыль \\
\hline Канада & материальный актив & $\begin{array}{l}\text { подоходный налог; } \\
\text { налог на прибыль }\end{array}$ \\
\hline Мальта & ценные бумаги & $\begin{array}{l}\text { НДФЛ; } \\
\text { налог на прибыль }\end{array}$ \\
\hline Россия & имущество & $\begin{array}{l}\text { НДФЛ; } \\
\text { налог на прибыль }\end{array}$ \\
\hline Сингапур & услуга & $\begin{array}{l}\text { корпоративный налог; } \\
\text { налог на товары и услуги }\end{array}$ \\
\hline США & имущество & $\begin{array}{l}\text { налог на имущество; } \\
\text { налог на годовой валовый доход; } \\
\text { налог на прибыль; } \\
\text { налог на прирост капитала; } \\
\text { зарплатные налоги }\end{array}$ \\
\hline Швейцария & валюта & налог на доход \\
\hline Швеция & валюта & налог на доход \\
\hline Япония & платежное средство & налог на доход \\
\hline
\end{tabular}

Источник: [12]

Особый порядок налогообложения операций с криптовалютами и их налогового администрирования не установлен ни одной главой Налогового кодекса РФ. Информационную базу налогового регулирования составляют письма ФНС России или Министерства финансов РФ, содержащие ответы на частные вопросы по налогообложению доходов организаций или физических лиц при совершении ими операций с криптовалютами.

Тем не менее, детализации использования криптовалют в хозяйственной деятельности организаций до сих пор не продемонстрировано законодательно, несмотря на наличие такой формы предпринимательства, как майнинг (создание и операции с криптовалютами). Поэтому актуальность вопросов правового регулирования правовых и налоговых отношений в условиях интенсивно развивающейся цифровой экономики на современном этапе не вызывает сомнений.

При создании единицы криптовалюты появляются вещные права, так как возникает возможность пользования, владения, распоряжения, купли-продажи, мены. Вместе с тем при применении гражданского законодательства возникает проблема восстановления нарушенных вещных прав и наложения судом обеспечительных мер. При таких обстоятельствах возникает необходимость решения проблемы с помощью включения криптовалют в перечень объектов гражданских правоотношений. Что в свою очередь, не затрагивает нарушение государственной монополии на эмиссию денег. Российская платежная система QIWI готова выпустить в оборот битрубль, но отсутствие разрешения Банка России тормозит данный процесс.

Таким образом, современные новейшие финансовые отношения и их правовое и налоговое регулирование, по всей видимости, подлежат глубокому исследованию с позиций определения понятия электронных денег для целей налогообложения; рассмотрения и изучения специфики данных правоотношений как объекта налогообложения; исследований зарубежных моделей правового регулирования налогообложения в цифровой экономике; создания правовых отношений и их регулирования при налогообложении криптовалют в РФ.

Все это требует совершенствования норм Гражданского, Налогового кодексов РФ и других видов законодательства, поскольку криптовалюты в настоящее время активно используются во взаиморасчетах и не являются электронными денежными средствами, иностранной валютой, объектом гражданских прав, несмотря 
на проект закона «О цифровых финансовых активах», который будет регулировать четыре типа цифровых финансовых отношений: криптовалюты; технологию их добычи (майнинг); процедуру первичного финансирования проектов с помощью токенов (ICO); а также технологию распределенного хранения информации (блокчейн) и связанные с ней смарт-контракты. Все криптовалюты и токены, используемые при ICO, объединятся в законопроекте понятием цифрового финансового актива, суть которого имущество в электронной форме, созданное с использованием шифровальных (криптографических) средств, где правовой статус цифровых финансовых активов приравнивается к иному имуществу, наряду с интеллектуальной собственностью, материальными ценностями, безналичными денежными средствами и т. п. [4]. Так, при рассмотрении криптовалюты как платежного инструмента и средства накопления, операции с ней могут подпадать под соответствующее регулирование. Потенциально это может быть законодательство о банковской деятельности, специализированное законодательство о платежных системах и т. п. Тогда налогообложение будет не собственно операций с криптовалютой, а экономической выгоды, возникшей от реализации активов.

Формирование цифровой экономики является процессом глобальных изменений во всех сферах деятельности, в особенности государственного управления. Появление в экономике России новейших финансовых инструментов, основанных на цифровых технологиях, требует решения целого ряда проблем в налогообложении. Причем в скорейшем решении вопросов налогообложения заинтересовано не только государство, но и участники рынка - налогоплательщики, так как отсутствие конкретных правовых аспектов определения цифровых денег не представляет возможности внесения изменений в Налоговый кодекс и другие законодательные акты о налогах и сборах Российской Федерации.

\section{Библиографический список}

1. Гражданский кодекс Российской Федерации (ГК РФ) от 30.11.1994 г. № 51-Ф3 (ред. от 03.08.2018 г.) [Электронный ресурс]. Режим доступа: Справочная правовая система «КонсультантПлюс» http://www.consultant.ru/cons/ (дата обращения: 01.02.2019).

2. Федеральный закон «О валютном регулировании и валютном контроле» от 10.12.2003 г. № 173-Ф3 (ред. от 25.12.2018 г.) [Электронный ресурс]. - Режим доступа: Справочная правовая система «КонсультантПлюс» http://www.consultant.ru/ cons/ (дата обращения: 06.02.2019).

3. Федеральный закон «О национальной платежной системе» от 27.06.2011 г. № 161-Ф3 (ред. от 27.06.2018 г.) (с изм. и доп., вступ. в силу с 26.09.2018 г.) [Электронный ресурс]. - Режим доступа: Справочная правовая система «КонсультантПлюс» http://www.consultant.ru/cons/ (дата обращения: 01.02.2019).

4. Федеральный закон «О цифровых финансовых активах» Проект № $419059-7$ [Электронный ресурс]. - Режим доступа: Справочная правовая система «КонсультантПлюс» http://www.consultant.ru/cons/ (дата обращения: 01.02.2019).

5. Бабкин. А. В. и др. Формирование цифровой экономики в России: сущность, особенности, техническая нормализация, проблемы развития / А. В. Бабкин, Д. Д. Буркальцева, Д. Г. Костень, Ю. Н. Воробьев // Научно-технические ведомости СПбГПУ. Экономические науки. - 2017. - Т. 10. - № 3. - С. 9-25.

6. Капранова, Л. Д. Цифровая экономика в России: состояние и перспективы развития [Электронный ресурс] // Экономика. Налоги. Право. - 2018. - Т. 11. - № 2. - Режим доступа: https://doi.org/10.26794/1999-849X-2018-11-2-58-69 (дата обращения: 14.02.2019).

7. Комиссарова, М. С. Внедрение информационных технологий в систему налогового контроля в условиях цифровизации экономики [Электронный ресурс] / М. С. Комиссарова, Н. В. Рудченко // Молодой ученый. - 2018. - № 52. - С. 120-123. Режим доступа: https://moluch.ru/archive/238/55172/ (дата обращения: 04.02.2019).

8. Пшеничников, В. В. Дискуссии о необходимости единой мировой валюты в условиях глобализации и многополярности современного мира [Электронный ресурс] // Научно-технические ведомости Санкт-Петербургского государственного политехнического университета. Экономические науки. - 2015. - № 2 (216). - С. 7-17. - Режим доступа: https://elibrary. ru/item.asp?id=23373875 (дата обращения: 01.02.2019). DOI: 10.5862/JE.216.1

9. Пшеничников, В. В. Электронные деньги как фактор развития цифровой экономики [Электронный ресурс] / В. В. Пшеничников, А. В. Бабкин // Научно-технические ведомости СПбГПУ. Экономические науки. - 2017. - Т. 10. № 1. - Режим доступа: https://cyberleninka.ru/article/v/elektronnye-dengi-kak-faktor-razvitiya-tsifrovoy-ekonomiki (дата обращения: 05.02.2019).

10. Рагимова, С. Глоссарий цифровой экономики [Электронный ресурс] // Forbes. - Режим доступа: http://www.forbes.ru/ brandvoice/sap/356277-glossariy-cifrovoy-ekonomiki (дата обращения: 01.02.2019). 
11. Единый портал бюджетной системы Российской Федерации «Электронный бюджет» [Электронный ресурс]. - Режим доступа: http://www.budget.gov.ru/ epbs/faces/page_home?_adf.ctrl-state=ao9dyvuj1_4\&regionId=45 (дата обращения: 10.02.2019).

12. Информационный ресурс о цифровых валютах «Coinspot» [Электронный ресурс]. - Режим доступа: htpp://coinspot/tol technology $\backslash$ bitcoin $\backslash$ (дата обращения: 05.02.201).

13. Электронные сервисы [Электронный ресурс] // Официальный сайт Федеральной налоговой службы Российской Федерации. - Режим доступа: https://www.nalog.ru/rn77/about_fts/el_usl/ (дата обращения: 01.02.2019).

\section{References}

1. Grazhdanskii kodeks Rossiiskoi Federatsii ot 30.11.1994 g. № 51-FZ (red. ot 03.08.2018 g.) [The civil code of the Russian Federation (civil code) dated November 30, 1994 № 51-FZ (ed. on August 03, 2018)]. Available at: Spravochnaya pravovaya sistema «Konsul’tantPlyus» http://www.consultant.ru/cons/ (accessed 01.02.2019).

2. Federal'nyi zakon «O valyutnom regulirovanii i valyutnom kontrole» ot 10.12 .2003 g. № 173-FZ (red. ot 25.12 .2018 g.) [Federal law «On currency regulation and currency control» dated December 10, 2003 № 173-FZ (ed. on December 25, 2018)]. Available at: Spravochnaya pravovaya sistema «Konsul'tantPlyus» http://www.consultant.ru/cons/ (accessed 06.02.2019).

3. Federal'nyi zakon «O natsional'noi platezhnoi sisteme» ot 27.06.2011 g. № 161-FZ (red. ot 27.06.2018 g.) (s izm. i dop., vstup. v silu s 26.09.2018 g.) [Federal law «On the national payment system» dated June 27, 2011 № 161-FZ (ed. of 27.06.2018 g.) (with izm. and DOP., entry. in force with September 2, 2018)]. Available at: Spravochnaya pravovaya sistema «Konsul'tantPlyus» http://www.consultant.ru/cons/ (accessed 01.02.2019).

4. Federal'nyi zakon «O tsifrovykh finansovykh aktivakh» Proekt № 419059-7 [Federal law «On digital financial assets» Project № 419059-7]. Available at: Spravochnaya pravovaya sistema «Konsul'tantPlyus» http://www.consultant.ru/cons/ (accessed 01.02.2019).

5. Babkin A. V., Burkal'tseva D. D., Kosten' D. G., Vorob'ev Yu. N. Formirovanie tsifrovoi ekonomiki v Rossii: sushchnost', osobennosti, tekhnicheskaya normalizatsiya, problemy razvitiya [The emergence of digital economy in Russia: its essence, features, technical normalization, the problems of development]. Nauchno-tekhnicheskie vedomosti SPbGPU. Ekonomicheskie nauki, 2017, Vol. 10, I. 3, pp. 9-25.

6. Kapranova L. D. Tsifrovaya ekonomika v Rossii: sostoyanie i perspektivy razvitiya [Digital economy in Russia: state and prospects of development]. Ekonomika. Nalogi. Pravo, 2018, Vol. 11, I. 2. Available at: https://doi.org/10.26794/1999849X-2018-11-2-58-69 (accessed 14.02.2019).

7. Komissarova M. S. Vnedrenie informatsionnykh tekhnologii v sistemu nalogovogo kontrolya v usloviyakh tsifrovizatsii ekonomiki [Introduction of information technologies in the system of tax control in the conditions of digitalization of the economy]. Molodoi uchenyi [Young scientist], 2018, I. 52, pp. 120-123. Available at: https://moluch.ru/archive/238/55172/ (accessed 04.02.2019).

8. Pshenichnikov V.V. Diskussii o neobkhodimosti edinoi mirovoi valyuty v usloviyakh globalizatsii i mnogopolyarnosti sovremennogo mira [Discussions on the need for a single world currency in the context of globalization and multipolarity of the modern world]. Nauchno-tekhnicheskie vedomosti Sankt-Peterburgskogo gosudarstvennogo politekhnicheskogo universiteta. Ekonomicheskie nauki, 2015, I. 2 (216), pp. 7-17. Available at: https://elibrary.ru/item.asp?id=23373875 (accessed 01.02.2019). DOI: 10.5862/JE.216.1.

9. Pshenichnikov V. V., Babkin A. V. Elektronnye den'gi kak faktor razvitiya tsifrovoi ekonomiki [Electronic money as a factor in the development of the digital economy]. Nauchno-tekhnicheskie vedomosti SPbGPU. Ekonomicheskie nauki, 2017, Vol. 10, I. 1. Available at: https://cyberleninka.ru/article/v/elektronnye-dengi-kak-faktor-razvitiya-tsifrovoy-ekonomiki (accessed 05.02.2019).

10. Ragimova S. Glossarii tsifrovoi ekonomiki [Glossary of digital economy]. Forbes. Available at: http://www.forbes.ru/brandvoice/ sap/356277-glossariy-cifrovoy-ekonomiki (accessed 01.02.2019).

11. Edinyi portal byudzhetnoi sistemy Rossiiskoi Federatsii «Elektronnyi byudzhet» [Unified portal of the budget system of the Russian Federation «Electronic budget»]. Available at: http://www.budget.gov.ru/epbs/faces/ page_home?_adf.ctrl-state=ao9dyvuj1_4\&regionId=45 (accessed 10.02.2019).

12. Informatsionnyi resurs o tsifrovykh valyutakh «Coinspot» [Information resource about digital currencies «Coinspot»]. Available at: htpp://coinspot/toltechnologylbitcoin $\backslash$ (accessed 05.02.2019).

13. Elektronnye servisy [Electronic services] Ofitsial'nyi sait Federal'noi nalogovoi sluzhby Rossiiskow Federatsii [Official website of the Federal tax service of the Russian Federation]. Available at: https://www.nalog.ru/rn77/about_fts/el_usl/ (accessed 01.02.2019). 